of a corresponding vehicle which had been cleaned up on this brand of petrol. Others will doubtless follow in the drive for fuels with a better public health image and it will be gratifying to see this aspect dominating advertising campaigns instead of acceleration profiles.

\section{Ominous Absence}

A NoTABLE absentee from the IUPAC (International Union of Pure and Applied Chemistry) conference in Riga last week was Dr Františk Sorm, from the Czechoslovak Academy of Sciences.

Dr Sorm, whose research includes investigations of alkaloid synthesis, the discovery of new terpenoid structures (including the first detection of medium ring compounds in nature) and the synthesis of nucleic acid components and their analogues as cancerostatic agents, was scheduled to read a paper at the conference, but failed to arrive.

Recently, Dr Šorm was relieved of his post as president of the Czechoslovak Academy of Sciences, a position which he had held since 1962 . It is to be hoped that the absence of so eminent a scientist from the conference (his name appears on the membership lists of no less than eight foreign academies, including that of the Soviet Union) does not mean his further downgrading, or dismissal from his subsidiary post of director of the Institute of Organic Chemistry and Biochemistry of the Czechoslovak Academy.

\section{IBM}

\section{Entry of the Evolving Computer}

ON Tuesday this week the managing director of IBM (United Kingdom) Ltd, Mr E. R. Nixon, explained a promise that he made to the House of Commons Select Committee on Science and Technology earlier this year that the IBM factory in Hampshire will be used for the manufacture of a major new product. Mr Nixon announced that this is to be the largest model of a long awaited new range of IBM computers. Called the 370 system, the new range is a follow-on to the IBM 360 system of computers that has dominated much of the computer business since its introduction in 1964 when it was heralded as the first fully compatible family of computers.

The new range does not mark another of the quantum jumps in technology which people have come to expect as the way that the computer industry advances. In fact IBM representatives seem hard pressed to put a word to the 370 system in the way that the 360 system was described in a nutshell as third generation. It is true that the 370 system makes extensive use of what is termed monolithic systems technology, but then this technique of cramming circuits onto microscopic chips of material has already been used on some of the later machines of the 360 system. Then again, the way that the main store in the computers of the 370 system appears to have a faster cycle time than its rating because of what is known as a buffer memory, is already familiar to users of the 195 model of the 360 system.

The 370 system is not then the long-anticipated fourth generation of computers-the growth of computer technology now seems to be more like something out of Darwin's book than Planck's. Price and performance are what distinguishes the 370 system from its predecessors, IBM says, and Mr Nixon's account of the new system last week was liberally sprinkled with descriptions of how it is faster, or cheaper, or has a larger memory, than comparable computers in the 360 system.

According to the scheme by which IBM has carved up the world, the factory of IBM (UK) at Havant in Hampshire, which for no obvious reason suddenly doubled in size and thus attracted the curiosity of the Select Committee earlier this year, is to manufacture all the model 165 computers of the 370 system to be sold outside North America. This is the largest of the two machines at present making up the 370 system, and the North American market will of course be supplied from the IBM factories in the United States. American computer firms with factories in Britain are always

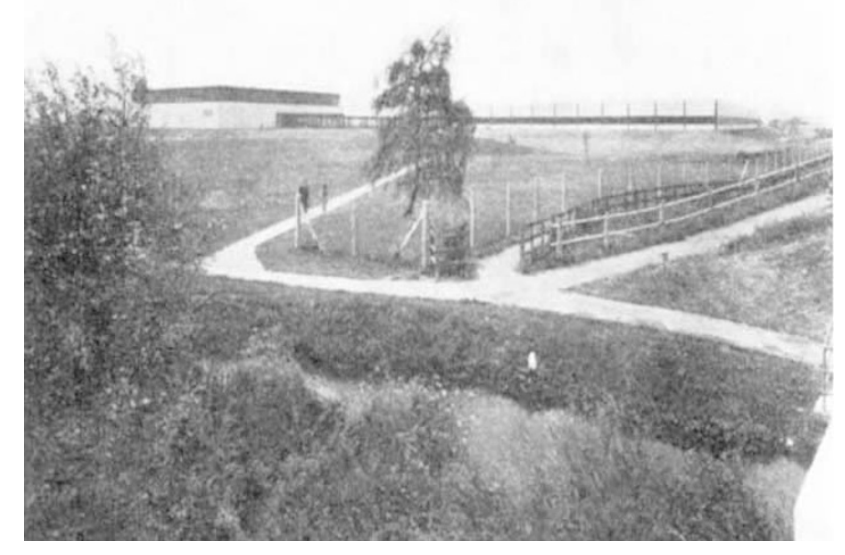

The IBM factory at Havant, Hampshire.

eager to prove themselves as obliging guests, and $\mathrm{Mr}$ Nixon said he anticipates that the 165 machine will make a very positive contribution to the balance of payments. But he declined to say at this stage to what extent the new machine will contain British components. This of course is one of the factors which decides whether a particular computer is to be purchased by the British government in preference to a foreign machine, and in the past $\mathrm{Mr}$ Nixon has claimed that IBM (UK) has not received the preference that it deserves. In a prod at the computer purchasing authorities, Mr Nixon said on Tuesday that the $370 / 165$ is "ideally suited for many large-scalc government applications".

Testing of the prototype 165 has already begun at Havant, and the first production models are expected to leave the factory in the second quarter of next year.

The second, smaller, machine in the 370 system is the model 155, and the Montpellier factory of IBM (France) is to manufacture those that are to be sold outside North America. IBM factories in France (Essonnes) and Germany (Sindelfingen) will be making the micro- 